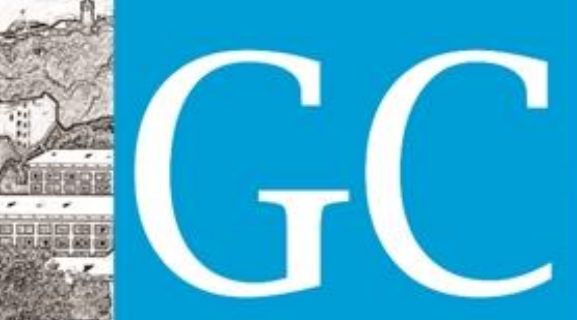

ISSN 2318-8472

Revista Nacional de

Gerenciamento de Cidades

\title{
"Casarões" de Bocaina: Mapeamento por meio da linguagem arquitetônica
}

\author{
"Big Houses" of Bocaina: Mapping through the architectural language \\ "Caserones" de Bocaina: Mapeo por medio del lenguaje arquitectónico
}

\author{
Ana Laura Assumpção \\ Doutoranda, IAU-USP, Brasil \\ alauraassumpcao@gmail.com
}

Paulo César Castral

Professor Doutor, IAU-USP, Brasil. pcastral@usp.br 


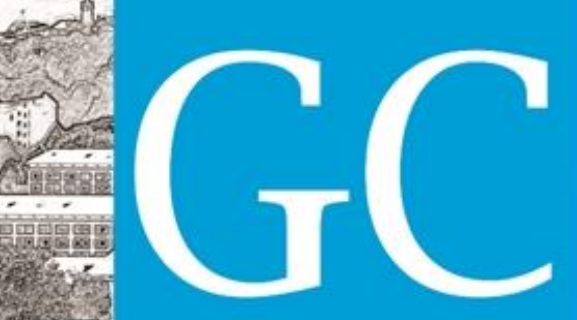

\section{Revista Nacional de}

Gerenciamento de Cidades

con el objetivo de investigar la percepción de la población en relación con el patrimonio, así como su papel en su preservación, pudiendo direccionar estrategias de preservación en el ámbito de las políticas públicas.

PALAVRAS-CHAVE: Património. Lenguaje arquitectónico. Bocaina. 


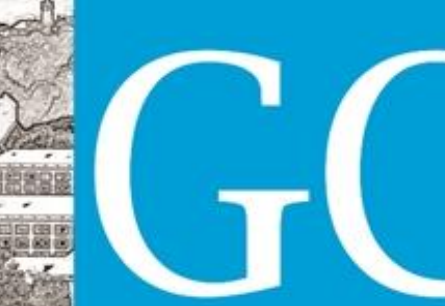

Revista Nacional de

Gerenciamento de Cidades

\begin{abstract}
Associando a noção de ambiente à de patrimônio urbano, ela induz a reflexão e a prática patrimonial a se abrirem para os valores pelos quais os habitantes das cidades reconhecem nelas, mais do que um simples pano de fundo, um cenário morto em relação ao qual suas vidas seriam indiferentes. Esta ótica permite trabalhar com os sentidos de lugar associados às estruturas materiais preservadas (naturais ou edificadas). (ARANTES, 2006, p. 430)
\end{abstract}

O vínculo da noção de cidade como bem cultural com a ação humana possibilita, assim, um pensamento que parte de um entendimento do mental para a aplicação no concreto, ou seja, através da percepção, dos sentidos, da cognição e mais, da memória e da identidade, pertencer ao lugar, àquele bem. "O patrimônio pode ser integrado às culturas locais ou recusado por elas; tudo depende dos usos sociais a que vier a servir" (ARANTES, 2009, p. 17). É o contato das pessoas com seu ambiente e as diferentes sensações a que são envolvidas - adquiridas pela corporeidade que é ligação com mundo e quem possibilita o ato perceptivo e a relação afetiva - que abarcam as noções de pertencimento e de identidade do lugar. Entendendo lugar aqui, segundo Antonio Arantes (2009, p. 18), como espaço apropriado pela ação humana.

\begin{abstract}
A identidade do lugar está intimamente ligada à relação que as pessoas têm com o mesmo, e com a capacidade de mexer com os sentimentos individuais e/ou colectivos. Assim sendo, a identidade deve ser capaz de incorporar a história e a cultura de uma determinada sociedade, de um determinado lugar. (BAPTISTA, 2013, p. 51)
\end{abstract}

Determinado lugar, como espaço da experiência, carrega uma história que diz respeito a um grupo social, localizados em um espaço e em um tempo também determinados. Participantes dessa história estão os elementos, de certa maneira, materiais e os elementos relativos a valores imateriais, que incluem desde a presença de edifícios, de monumentos símbolos, de conjuntos urbanos, até os costumes populares, como festas, músicas e comidas típicas. Todos esses elementos corroboram para o sentimento de identidade, de pertencimento e se relacionam intrinsecamente com as questões patrimoniais.

o sentimento de pertencer a coletividades nacionais, regionais ou locais assim como de ocupar posição reconhecível no mapa social ganham nova significação e importância, que se manifestam na construção de sentidos de lugar e incluem demandas de natureza patrimonial. (ARANTES, 2006, p. 430)

É diante desse contexto que a cidade de Bocaina aparece no presente artigo. Relevante por ainda manter a peculiaridade da formação das cidades do interior de São Paulo, Bocaina possui diversos "casarões" remanescentes da época do auge da cafeicultura paulista, no final do século XIX e início do século XX. Sem ter qualquer intervenção governamental, o cuidado para com esses bens arquitetônicos parece vir dos próprios moradores, possivelmente entendido pela noção de pertencimento do lugar. Tem-se como pressuposto a ideia de que o espírito preservacionista dos moradores é o que mantém erguido grande parte dessas edificações até hoje. 



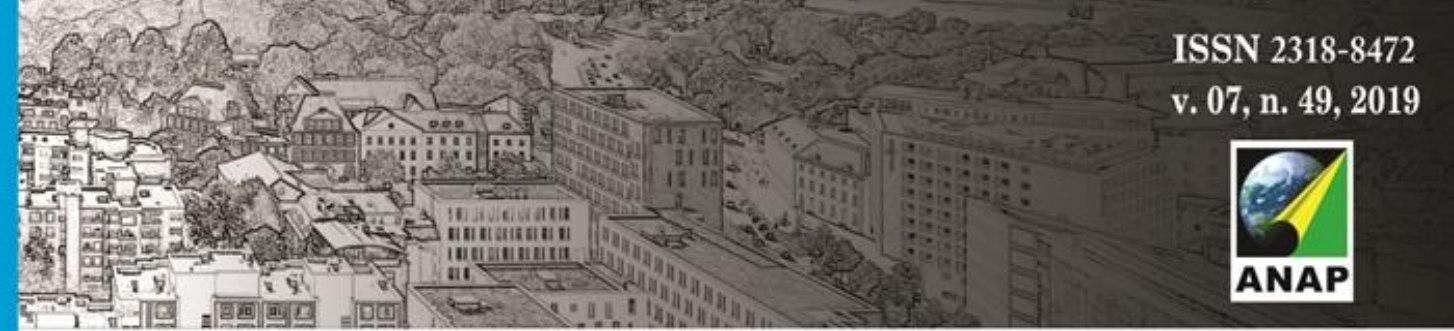

Revista Nacional de

Gerenciamento de Cidades

modernização da cidade. (LIMA, 2008, p. 12)

Com a produção eclética vê-se uma distinção das características da arquitetura tradicional quanto ao alinhamento do lote, a complexidade dos telhados, a espaços livres, a quantidade de ornamentos, a presença de platibanda. Segundo Carlos Lemos (1999, p. 253), chegaram os telhados recortados por águas-furtadas, as casas de esquina com vasto alpendre dando para um jardim lateral sempre florido, as casas de aluguel no alinhamento, mas com um corredor descoberto com um seguro portão de ferro forjado. Além disso, "cada vez mais presentes nas construções, as platibandas começaram a ser adornadas com os mais variados estilos de ornamentos". (ARRUDA, 2017, p. 368). Inclusive aparecem estátuas, vasos, globos, pinhas, balaústres, de modo a incrementar a fachada das edificações.

Surge também no ecletismo a tipologia de casas com porão alto, primeiramente mantendo seu alinhamento no lote e gradativamente se soltando no lote, possuindo recuos laterais até se afastar totalmente da rua. (ARRUDA, 2017, p. 368). As residências deveriam contar, obrigatoriamente, com porões para arejamento e ventilação, exigência de caráter sanitário e de higiene, além de ser uma questão de status da residência. (LODY, 2015, p. 137). Esse tipo de caracterização foi claramente observado na análise da linguagem arquitetônica das casas de Bocaina.

Uma das tendências arquitetônicas levantadas nesse breve estudo é o chamado chalé, ou então chalet, no francês.

Fruto do Romantismo do século XIX, e muito popular no último terço do oitocentismo, o chalé assumiu alto valor simbólico - embora de significado ambíguo -, por estar ligado tanto à noção de uma idealizada vida campestre, quanto à de modernidade técnica, que então se introduzia em São Paulo. (CAMPOS, 2008, p. 47)

Essa modalidade de edificação tem origem no movimento pitoresco inglês da primeira metade do século XVIII. Quanto às suas características, de início, configurava-se pela sua forma vernacular bastante simples, de madeira, típica da região rural da Suíça. Em geral, com plantas retangulares e telhado de duas águas, com suave inclinação, disposto de modo a voltar uma das empenas para a frente. (CAMPOS, 2008, p. 51)

No entanto, sofreu alterações, inclusive por arquitetos eruditos europeus, uma vez que algumas de suas características não se encaixavam aos novos conceitos de higiene e conforto. Progressivamente, o modelo chalé - não só se encontrava apenas no ambiente rural como foi incorporado ao urbano - foi se difundindo, chegando aos países através das revistas, da possibilidade de possuir novos materiais advindos com a ferrovia e se transformando, sendo adaptado a cada lugar e a cada gosto, inclusive incorporado ao estilo eclético. No Brasil, não foi diferente. $O$ chalé acabou por guardar características como: telhado de duas águas com empena para a frente e largos beirais, além de adquirir uma decoração bastante usual: os lambrequins, "que tanta personalidade conferia aos chalés ecléticos de meados do oitocentismo, não pertencia de fato à construção rústica de estilo alpino." (CAMPOS, 2008, p. 53). Em Bocaina, o que percebe são essas características pontuais dos chalés mescladas a outros estilos 


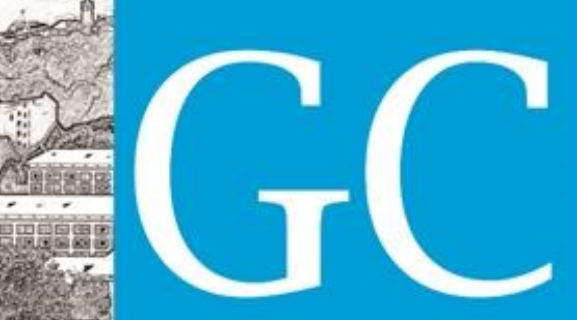

\section{Revista Nacional de}

Gerenciamento de Cidades

\section{CONSIDERAÇÕES FINAIS}

Nesse estudo não coube discutir a posição das tendências arquitetônicas, mas entender que a produção da arquitetura, no caso do interior paulista, configura-se como representativa de um período histórico, de uma sociedade e da configuração de um espaço urbano, a ver Bocaina.

Mais do que isso, esse estudo surge como uma maneira de apresentar e mostrar a preciosidade de Bocaina, a qual ainda guarda tanto a configuração quanto a arquitetura da cidade original.

A falta de interesse nas edificações do final do século XIX e início do século XX tende a fazer com que esses bens desapareçam e com isso, desapareça uma parte de uma história que nos diz respeito. Enquanto Bocaina ainda conserva, de um modo geral, a sua produção arquitetônica original é preciso levantar a importância disso e desenvolver cada vez mais estudos - este sendo um deles - que possam engatilhar ações preservacionistas de cunho oficial, para que a sobrevivência desses bens patrimoniais não dependa apenas da boa vontade da população, como parece ocorrer nos dias atuais. Já dizia Carlos Lemos (1989, p. 191),

\footnotetext{
nossa esperança salvaguardadora também está nas cidades do interior, aquelas crescidas sob a égide do café, que até certo ponto, construíram verdadeiras projeções da capital. [...] Afinal o café que nos fez não pode ser esquecido assim. (LEMOS, 1989, p. 191)
}

\section{REFERÊNCIAS BIBLIOGRÁFICAS}

ARANTES, A. A. O patrimônio cultural e seus usos: a dimensão urbana. Revista Habitus, v. 4, 2006, p. 425-435.

. Patrimônio cultural e cidade. In: FORTUNA, C.; LEITE, R. P. Plural de cidades: novos léxicos urbanos. Coimbra: Ed. Almedina, 2009, p. 11-24.

ARRUDA, T. C. Ornamentos de platibanda em edificações de Belém entre os séculos XIX e XX: inventário e conservação. In: Anais do Museu Paulista. Nova série, v. 25, n. 3. São Paulo, set/dez 2017, p. 341-388.

ATIQUE, F. Arquitetanto a "Boa-Vizinhança”: a sociedade urbana do Brasil e a recepção do mundo norte-americano, 1876-1945. Tese de Doutorado - FAU-USP. São Paulo, 2007.

BAPTISTA, A. D. O lugar como simbiose: centro histórico de Torres Vedras. Dissertação de Mestrado Integrado em Arquitectura. Universidade Lusófona de Humanidades e Tecnologias. Lisboa, 2013.

BEZERRA DE MENEZES, U. T. A cidade como bem cultural: áreas envoltórias e outros dilemas, equívocos e alcance da preservação do patrimônio ambiental urbano. In: MORI, V. H. et. al. [orgs]. Patrimônio: atualizando o debate. São Paulo: 9a SR/IPHAN, 2006.

CAMPOS, E. Chalés paulistanos. Anais Do Museu Paulista: História E Cultura Material, 16(1), 2008, p. 47-108.

CORREIA, T. de B. Art déco e indústria, Brasil décadas de 1930 e 1940. Anais do Museu Paulista (Impresso), v. 16, n. 2, 2008, p. 47-104.

CURY, I. [org]. Cartas patrimoniais. Brasília: IPHAN, 2000. 
